\title{
Social Media for Social Inclusion: Barriers to Participation in Target-Language Online Communities
}

Ellen Yeh E Nicholas Swinehart

Many learners, even those studying at universities in regions where the target language is spoken, lack opportunities for meaningful language use outside of the classroom. One avenue for learners to increase authentic target-language communication is online affinity spaces within social media platforms, where interactions with other users are formed around shared interests rather than personal connections. International students at an arts and media college in the Midwestern United States were asked to read a discussion thread within a social media platform, summarize what they found useful, and respond to pre- and posttask questionnaires. The platform used, Reddit, features anonymous user-generated content in a wide range of discussion forums based around specific interests and geographic locations. This study used qualitative data to investigate the extent to which international students participate in online communities like these and the factors or barriers that keep them from achieving full participation. The findings are then used to present learner training strategies that can help reduce or remove those barriers, enabling language learners to increase their participation in targetlanguage online communities.

Plusieurs apprenantes et apprenants, même parmi celles et ceux qui étudient dans une université située dans une région où la langue cible est parlée, n'ont pas suffisamment d'occasions de pratiquer avantageusement leur nouvelle langue en dehors de la salle de classe. Une avenue qui s'ouvre à elles et à eux pour augmenter leurs chances de s'adonner à des communications authentiques dans leur langue cible est l'espace d'affinité en ligne sur les réseaux sociaux, endroit où les interactions sont davantage basées sur le partage d'intérêts communs que sur des relations personnelles. Des étudiantes et étudiants internationaux d'un collège des arts et des médias du Midwest des États-Unis ont été invités à lire un fil de discussion sur une plateforme de réseau social, à en résumer les éléments jugés utiles et à répondre à un questionnaire avant et après l'exercice. La plateforme utilisée, Reddit, présente des contenus qui sont générés anonymement par les utilisateurs dans un large éventail de forums de discussion et qui sont regroupés autour d'intérêts et de secteurs géographiques particuliers. Cette étude utilise des données qualitatives permettant d'évaluer dans quelle mesure les étudiantes et étudiants internationaux participent à la vie de communautés en ligne de ce genre et de déterminer quels sont les facteurs ou obstacles qui les empêchent de le faire pleinement. Les constatations sont ensuite utilisées pour présenter des stratégies 
de formation des apprenantes et apprenants qui sont susceptibles d'aider à réduire ou aplanir ces obstacles et à aider par le fait même les participants à s'impliquer davantage dans la vie de communautés en ligne s'exprimant dans leur langue cible.

KEYWORDS: barriers, digital divide, participation, social inclusion, social media

\section{Introduction}

Many prominent language education theories and approaches (e.g., sociocultural theory, communicative language teaching) place an emphasis on the need for learners to use the target language for authentic, meaningful communication with others. But many learners, even those studying at universities in regions where the target language is spoken, lack opportunities for meaningful language use outside of the classroom (Glass \& Westmont, 2014; Hendrickson et al., 2011; Zhang \& Goodson, 2011). They can often find it difficult to gain access to social groups and events, instead, spending much of their free time with other speakers of their first language (Hendrickson, 2018).

Social media platforms are powerful tools for social engagement and participation (Jenkins, 2006) and are one way to increase opportunities for language learners to use the target language in authentic contexts. This can be particularly useful for learners who have limited opportunities for participation in target-language communities, as computer-mediated communication $(\mathrm{CMC})$ offers more egalitarian participation than face-to-face discussions for those who used to remain silent during traditional conversations (Warschauer, 1997), and because the ability to access, adapt, and create new knowledge online is critical to social inclusion (Warschauer, 2003). Whereas previous studies have discussed benefits and examples of such participation (Thorne et al., 2015), there is limited research on factors that may keep learners from using the target language online.

This article discusses research examining English language learners' (ELLs') perceptions of a social media platform that features discussions among anonymous users centred around topics of interest within online affinity spaces. Gee (2004) describes affinity spaces as social areas, either physical or virtual, where common endeavour is primary, where experienced and inexperienced users share a common space, and there are many different routes to participation (pp. 77-79). The research presented here examines findings from a wider exploratory study where participants received initial training on the use of the Reddit platform and were then asked to read a discussion thread about the city in which they were living. In that study, 41 of 66 participants $(62.12 \%)$ said they always or usually use their first language, rather than English, on social media. This article reports results from pre- and posttask questionnaires to identify common barriers that prevent ELLs from 
using English online and present learner training strategies that can help reduce or remove those barriers, enabling language learners to increase their participation in target-language online communities.

\section{Literature Review}

One crucial way that $\mathrm{CMC}$ has been used for language learning is to provide learners access to participatory culture environments, which allow opportunities to use the target language for collaboration and communication (Dooly, 2015; Jenkins, 2006; Kessler, 2013). Social media has been one of the most popular tools language learners use for communication, and offer potential for social inclusion as well (Anwaruddin, 2019; Liu et al., 2015; Toetenel, 2014; Warschauer, 2003). This section outlines previous literature on the benefits and challenges regarding social inclusion for language learners, how CMC can be utilized to increase social inclusion, and barriers that can limit learners' inclusion in online environments.

\section{Social Inclusion}

The important issues of social inclusion have been raised and called for action in many computer-assisted language learning (CALL) conferences and journals in recent years. In 2015, the EuroCALL Conference challenged administrators and educators to explore the power, inequality, and diverse sociocultural contexts of language education outside the four walls of the classroom, whereas the Computer Assisted Language Instruction Consortium (CALICO) Journal published a special issue titled "Moving Forward with Critical CALL to Promote Social Inclusivity" in 2019 that explores the relationship between CALL and issues of social injustice, power, and inequality. According to Guo and Beckett (2007), "the increasing dominance of the English language is contributing to neocolonialism by empowering the already powerful and leaving the disadvantaged further behind" (p. 117). Research questions such as how educators and administrators can leverage technology to promote social inclusion in the curriculum (Warschauer, 2003) and how technology plays a role in the current social and political dynamic need to be further explored.

The concept of social inclusion is not only the problem of inadequate sharing of resources but also refers to the extent that individuals are able to engage in families, communities, society, and further take charge of their own destinies (Warschauer, 2003). The notion has to take into account a myriad of factors regarding both individual and social issues, including economic resources, health, education, recreation, identity, language, culture, and civic engagement (Castells, 1997; Stewart, 2000).

The notion of digital divide was utilized to analyze the complex layers of social inclusion issues in Warschauer's (2003) book titled Technology 
and Social Inclusion. To achieve social inclusion across the digital divide, obtaining access to physical resources such as computers and connectivity is necessary but insufficient; it is also crucial to ensure individuals have additional, complementary resources and interventions to develop the knowledge and skills required to use technology effectively. The physical availability of computers and connectivity has been overemphasized while ignoring the problems of content, language, literacy, and community and social resources, with language being one of the most critical and complex elements relevant to social inclusion in CMC environments (Warschauer, 2003). Language affects and interconnects with a variety of social divisions in terms of ethnicities, nationalities, economics, culture, and education. In addition, language has a significant influence on not only the ways diverse groups access and create information online but also how they form and express their cultural identities. One goal of using CMC with marginalized or diverse cultural groups is to foster the process of social inclusion and emphasize the transformation technology can bring, rather than the technology itself (Jarboe, 2001). Therefore, when discussing the role of technology in social inclusion, it is imperative to shift the emphasis from the "gaps to be overcome by provision of equipment" to "social development issues to be addressed through the effective integration of ICT into communities, institutions, and societies" (Warschauer, 2003, p. 9).

Rather than focusing on a digital divide, defined as "inequality between 'haves' and 'have-nots' differentiated by dichotomous measures of access," educators should be aware of digital inequality (DiMaggio \& Hargittai, 2001), or "inequality among persons with formal access to the Internet" (p. i, emphasis in original). This digital inequality contains five key components: (a) inequality in technical apparatus, (b) inequality in autonomy of use, (c) inequality in skill, (d) inequality in the availability of social support, and (e) variation in use, or inequality in how and what technology is used for (e.g., improving social capital, increasing income, entertainment; Dimaggio \& Hargittai, 2001, pp. 9-12). Regardless of whether the focus is on a digital divide or digital inequality, it is essential for language educators to critically examine how they can leverage the technology available to them with their students to promote greater social inclusion (Gleason \& Suvorov, 2019, p. iii).

\section{Affordances of CMC on Social Inclusion}

Many previous studies have explored the ways CMC can benefit language learners by offering linguistic, affective, and interpersonal development and growth (e.g., Abrams, 2003, 2008; Darhower, 2002; Toetenel, 2014). Early $\mathrm{CMC}$ research highlighted opportunities for more equal participation, compared with traditional classroom discussion, by circulating interactional patterns more evenly among all participants and offering more opportunities for language learners who are timid or need more time to prepare for the 
conversation (Abrams, 2008; Kern, 1995; Sullivan \& Pratt 1996; Warschauer, 1996, 1997). The concept of intersubjectivity was used to explain how taking an active part in extended conversation and maintaining social space makes participants more inclined to achieve coherent and authentic communication (Darhower, 2002). Abrams's (2003) study reveals that one strategy language learners apply in CMC is to build speech communities and create rules for interaction collaboratively in a shared space so that they can help one another develop wider participant roles. These participant roles provide language learners opportunities to practice the target language in more diverse forms of discourse and offer a shared space for more extensive communication.

One of the most influential factors that triggers negotiation of meaning is when interlocutors have equal participation, namely, through increased interaction between language learners and more experienced target language speakers (Varonis \& Gass, 1985). With the emergence of Web 2.0 and social media, CMC in language learning has shifted from an alternative to classroom discussion to a way for learners to reach new target-language interlocutors, communities, and materials (Anwaruddin, 2019), with potential benefits including enhanced learner autonomy, increased opportunities for collaboration, and the promotion of constructivist knowledge-building experiences (Liu et al., 2015). Furthermore, researchers assert that social media increase language learners' social cohesion and peer-to-peer collaboration and interaction (Toetenel, 2014). Recent work has explored autonomous language learning in the digital wilds ${ }^{1}$, which often occurs in online affinity spaces such as interest groups, blogging and micro-blogging environments, multiplayer games, and fan communities, rather than more traditional social media environments like Facebook that tend to rely on offline connections and relationships (Thorne et al., 2015). Language educators can use bridging activities that introduce learners to environments and practices they may be likely to continue using outside of formal assignments, bridging the gap between formal, classroom instruction and informal, out-of-class free participation (Thorne \& Reinhardt, 2008). This use of online affinity spaces allows learners with limited personal connections in the target-language culture to access online communities within social media environments that are built around topics that are important to them, where they can use their knowledge and interests to interact with a diverse group of interlocutors.

\section{Barriers and Limitations to Language Learners' Online Participation}

Despite the fact that CMC can provide many affordances in language learning, it is important to analyze the barriers that may limit language learner participation within these environments-or may even amplify digital inequality. For instance, studies report that learners feel more anxious during the public discourse of communication in CMC environments, and power imbalances between language learners and more experienced target language 
speakers, including teacher-learner and peer interactions, can result in passive participation or "lurking" behaviour (Dooly, 2015; Ortega \& Zyzik, 2008).

Research has investigated the issue of unequal participation in a myriad of online platforms. The findings of a study analyzing virtual language environments revealed that language learners were more responsive to assessment-related activities than other tasks (Hampel \& Pleines, 2013). The low participation in online discussions showed a large gap in viewing and contributing to the content, less priority for online assignments, and various levels of digital literacy among language learners. In another study, a large gap among learners' engagement was due to learners receiving inadequate scaffolding, insufficient appropriate tasks that foregrounded language inquiry over technological learning, and limited teacher training in online courses (Yang \& Chen, 2007). Studies on language learning within learning management systems underscore low participation in a distance learning project (Comas-Quinn et al., 2012) and a project that combined blogs and video conferencing (Stickler \& Hampel, 2010). Both studies revealed possible reasons for low participation to be language learners' anxiety toward participation, lack of motivation to use the technology, inadequate e-literacy, and technical problems.

Although social media have generated high enthusiasm and expectations for language learning, the platforms have also generated skepticism and illusions (Zourou, 2012). Attempts to utilize Facebook for language learning have often simply used Facebook as an environment for classroom discussion, with limitations stemming from privacy concerns, distractions within the platform, lack of implementation knowledge, and disorganized discussions (Bouhnik \& Deshen, 2014). Regarding the less controlled environments of the digital wilds, Kessler (2013) warns of the "dark side" within the participatory cultures (e.g., trolling and privacy concerns) but stresses the importance of training learners to manage these issues.

Many studies discuss the affordances (Dooly, 2015; Jenkins, 2006; Kessler, 2013) and barriers to language learners' active participation and social inclusion in various online environments (Comas-Quinn et al., 2012; Hampel \& Pleines, 2013; Stickler \& Hampel, 2010; Yang \& Chen, 2007), but this study adds to the literature by identifying barriers for language learners' participation in online affinity spaces through the following research questions:

Research Question 1: What reasons do ELLs provide for not using English to communicate online as much as they would like?

Research Question 2: What reasons do ELLs provide for why they would not feel comfortable posting comments or asking questions within online affinity spaces? 
Research Question 3: What reasons do ELLs provide for why they would not use the platform in this study or others like it (where they can take part in discussions with anonymous users) outside of class?

\section{Method}

\section{Participants}

A total of 66 ELLs were recruited from first-year writing and speaking classes at an arts and media college in the Midwestern United States. Participants included degree-seeking, exchange, and visiting international students who have studied in an English-speaking country for at least 1 month to 4 years. Their language proficiency levels were high-intermediate to advanced. In total, 15 different first languages were identified among participants, including Chinese, Bengali, French, Korean, Italian, Japanese, Malay, Odia, Portuguese, Russian, Serbian, Spanish, Thai, Turkish, and Vietnamese.

\section{Platform}

This study uses the Reddit platform as an example of an online affinity space. Reddit is a collection of more than one million discussion forums built around specific topics, resulting in many online communities with distinct rules and norms across a shared platform. These forums can centre on general issues like movies, fashion, or sports, or particular topics like a specific TV show, makeup tips, or an individual sports team. There are also forums built around geographic or institutional locations, such as particular nations, states, cities, or universities. One site-wide characteristic is the anonymity of its users; discussions develop around shared interests, rather than offline networks and relationships. This grants ELLs access to an immense variety of online affinity spaces with just one username and platform but it also exposes them to a complex set of online norms and practices, as well as the bad actors that are always present in online environments.

\section{Data Collection and Procedure}

This article is part of a larger research study investigating ELLs' views toward anonymous online social media environments. Participants attended a learner training workshop to become familiar with the basic use of the Reddit platform. They then completed a 16-item pretask questionnaire with Likert-type scale, multiple choice, and short response questions about demographic information and previous social media practices (e.g., how many social media platforms they use in a typical week, and their familiarity with specific platforms popular in the United States), including the question of whether they use English to communicate online as much as they would like. This question was followed up with an open-ended prompt asking stu- 
dents to explain their responses, which comprise the data used to investigate the first research question in this study.

For the main task, participants read an online discussion thread selected by the researchers that was related to the students' daily lives: the issue of safety in the neighbourhood where their university is located. They were required to write a reflection summary by analyzing and evaluating the content in the thread, then complete an 18-item posttask reflection questionnaire with Likert-type scale and open-ended questions that investigated their attitudes toward the platform used in this study and its users. This questionnaire included Likert-type scale and follow-up open-ended questions about how comfortable they would feel posting questions or comments on this platform and whether they thought they would use the platform in the future. The responses to these questions comprise the data analyzed in the second and third research questions of this study, respectively. The current study only utilizes data from the pre- and posttask questionnaires that focus on the reasons participants do not use English online in general or why they would not use this platform in the future, to investigate the barriers ELLs encounter in an anonymous environment that may keep them from using the target language in online affinity spaces in the digital wilds.

\section{Data Analysis}

The first stage of data analysis used 4-point Likert-type scale questions coded from 1 = strongly disagree, $2=$ disagree, $3=$ agree, to $4=$ strongly agree, with some variation based on the nature of the question (i.e., very unlikely to very likely, or very uncomfortable to very comfortable). Researchers then examined the openended questions that corresponded to selected Likert-type scale responses (outlined in the Results and Discussion sections for each research question, below) for further analysis of factors influencing their participation. All openended data were coded separately by two researchers and categorized into emerging themes by using a descriptive coding (topic coding) method for the first cycle of coding (Miles \& Huberman, 1994; Saldaña, 2003, 2015; Wolcott, 1994), and the second cycle of the coding methods applied frequency counts (LeCompte \& Schensul, 1999) and pattern coding (Miles \& Huberman, 1994) for a closer look at emerging patterns. Pattern coding was used in this study because this method allows for "explanatory or inferential codes, ones that identify an emergent theme, configuration, or explanation" (Miles \& Huberman, 1994, p. 69).

\section{Results and Discussion}

This section addresses each research question in turn, presenting barriers to online participation ELLs reported through coded survey data and then 
strategies that language educators can utilize to help reduce these barriers (summarized in Table 4).

\section{Factors Influencing ELLs' Online Participation}

To answer the first research question regarding reasons ELLs provide for not using English online, participants who stated in the pretask questionnaire that they did not use English on social media platforms as much as they would like (44 out of 66 participants) were asked to explain their response. The emerging themes were language ability, sociocultural factors, cultural issues, and technical factors (see Table 1).

Table 1

Factors that Prevent ELLs from Using English to Communicate Online $(n=44)$

\begin{tabular}{ll}
\hline Themes & Participants' Explanations \\
\hline Language ability (22) & -hard to express myself in L2 (7) \\
& -English skills "not good enough" (7) \\
& -afraid of making mistakes or being judged (5) \\
& -hard to understand informal language (2) \\
& -need to translate (2) \\
\hline Sociocultural factors (18) & -use L1 to speak with friends and family (18) \\
\hline Cultural issues (3) & -few opportunities to communicate with English speakers (1) \\
\hline Technical factors (2) & -afraid of making cultural mistakes (2) \\
\hline
\end{tabular}

Note. Throughout each table, explanations and themes are not always equal because some participants gave multiple explanations within one theme, while other responses fit within a theme but lacked detail or explanation. ELL = English Language Learner; L1 = first language; $L 2$ = second language.

The most reported factor that hindered ELLs' use of English online was their perceived shortcomings in language ability, both in terms of the language they produce and the language they encounter online. One student said that, "I am worried about my grammar mistakes or some spelling mistakes but most worried about the meaning that I can't express well or sometimes it's wrong." Participants reported being self-conscious about how more experienced target-language speakers may judge their language use. One student explained, "I feel like I don't know about the American language habits. I fear to be exposed that I'm a foreigner." These results show that participants were anxious and concerned about exposing themselves as inexperienced language users while interacting in CMC settings, supporting previous literature indicating that a lack of language and literacy skills combined with imbalanced power relations among interlocutors could lead to reluctance to actively participate (Dooly, 2015; Ortega \& Zyzik, 2008; Warschauer, 2003). 
This also reinforces Warschauer (2003) highlighting language as one of the most critical factors in social inclusion.

The second most frequently discussed factor that limited participants' use of English online is that the majority of people they communicate with online, their friends and family, speak their first language; participants reported feeling very awkward using the target language or that they did not have people to practice the target language with online. They tended to view social media primarily as a way to maintain relationships with people overseas, rather than practice the target language. But it is important to note that these data are from the pretask questionnaire, and that all these participants first stated that they do not use English online as much as they would like; it can be inferred that they would use English online more if they had people to communicate with. This corresponds with a key goal of the use of online affinity spaces for language learning: finding communities based on shared interests, not personal connections (Sauro, 2017; Thorne et al., 2015). The fact that participants recognized the lack of opportunities to build speech communities and learn about rules to communicate in their target language in both face-to-face and traditional virtual settings supports the benefits of online affinity spaces, which foster wider participant roles and allow more routes to participation in collaboration and extensive communication (Abrams, 2003; Darhower, 2002; Gee, 2004; Liu et al., 2015).

The final two themes for this pretask research question were lack of cultural knowledge and technical issues. Due to limited background information and references from the target language culture, participants were afraid to make mistakes and failed to use language authentically, which would expose themselves as foreigners. This finding correlates with previous research emphasizing the importance of providing adequate scaffolding with tasks that focus not only on technological factors but that increases access to additional, complementary resources and interventions about cultural inquiry in online curricula (Kessler, 2013; Warschauer, 2003; Yang \& Chen, 2007). Regarding technical issues, participants stated that they preferred the layout and features of social media platforms popular in their home country. It is important to keep in mind that despite the global popularity of platforms like Facebook, Twitter, and Instagram, some students-particularly those from China-may not have much experience with them. This is one case where access to technology can have an impact on ELLs' ability to achieve social inclusion online.

\section{Reasons for Discomfort in Anonymous Online Environments}

To answer the second research question about why ELLs feel uncomfortable participating in target-language online environments, participants who stated on the posttask questionnaire that they would feel somewhat or very uncomfortable posting comments or asking questions on a website such as 
Reddit (18 out of 66 participants) ${ }^{2}$ were asked to explain their responses (see Table 2).

Table 2

Reasons ELLs Do Not Feel Comfortable Posting Comments or Asking Questions Online $(n=14)$

\begin{tabular}{ll}
\hline Themes & Participants' Explanations \\
\hline Prefer passive participation (6) & -not comfortable expressing opinions online (3) \\
& - "don't like to post" (3) \\
\hline Skeptical of other users online (5) & -general distrust of anonymous users (3) \\
& -people are ljudgmental online (2) \\
\hline Language ability (3) & -English not good enough (2) \\
& -afraid of making mistakes (1) \\
\hline
\end{tabular}

Note. ELL = English Language Learner.

Despite some similar reasons as the first research question (e.g., language ability), participants stated additional concerns specific to the public, online nature of anonymous online environments like Reddit. Although anonymous cultures online can have some benefits for freedom of expression and less judgement based on individual identities, participants indicated that the resources on this type of platform could also be deceiving because they do not know who provided the information. ELLs further explained the reasons they preferred to observe as a lurker instead of actively participating. One student said, "I don't feel comfortable to share my personal opinions or experiences in the public," and the reasons for several participants were fear of making mistakes both linguistically and culturally, failing to explain the content clearly, being judged by other users, and causing conflicts. This fear of being judged and skepticism of online content and other users' reactions show the digital inequality in availability of social support within the online community: participants feel like outsiders, rather than members of the community, and this influences their comfort level toward participation. They also fail to see CMC environments as opportunities for more equal participation (Warschauer, 1997), with traditional power structures being reinforced rather than transformed (Dooly, 2015; Ortega \& Zyzik, 2008).

\section{Continue Usage in the Real-World Setting}

To answer the third research question, participants who stated they were not very likely to continue using this platform or others like it outside of class on the posttask questionnaire ( 14 out of 66 participants, with no participants saying they were very unlikely to use it) were asked to explain their responses. Results revealed the negative impact of anonymity, the perceived higher credibility of alternate resources or environments, and affective factors (see Table 3). 
Table 3

Factors that Hinder ELLs from Using This or Similar Platforms

(Where ELLs Can Take Part in Discussions with Anonymous Users) Outside of Class ( $n=14)$

\begin{tabular}{ll}
\hline Themes & Participants' Explanations \\
\hline Anonymity (6) & -skeptical about credibility (4) \\
& - "don't like" (2) \\
\hline Prefer other resources/environments (5) & -use their own personal experience (2) \\
& -talk to people face-to-face (2) \\
& -use other sources (1) \\
\hline Affective factors (3) & -laziness (2) \\
& -feel anxious using social media (1) \\
\hline
\end{tabular}

Note. ELL = English Language Learner.

In response to this question, several participants stated that skepticism about the credibility of anonymous environments and reluctance to trust the sources reduce the likelihood they will use this platform in the future, while others expressed they found the content was not useful and preferred using their own resources/experiences. They also claimed that they will retrieve information from more reliable sources, such as government websites, libraries, journal articles, or news, rather than anonymous user-generated content. These students are right to be skeptical about what they read online, especially with anonymous users, but lack the ability or inclination to evaluate what they read based on its own merits (Kessler, 2013), choosing instead to ignore these environments altogether.

Affective factors were also an issue, with some participants feeling anxious while using social media with so many concerns in terms of how to use language appropriately, how to avoid cross-cultural misunderstanding, and the fear of revealing their identities as foreigners. These factors influencing engagement reinforces the notion of how digital inequality (DiMaggio \& Hargittai, 2001) hinders social inclusion. In this case, while participants have equal access to technical equipment, they expressed concerns that highlight their inequality in autonomy in social media use: feeling restricted from becoming an active agent in CMC settings, struggling to develop the linguistic skills and intercultural competence they deem necessary to communicate, and lacking community support while navigating these new online platforms in the target language. While considering these variables, some participants chose to simply give up using this platform as a potential tool for target language and culture learning opportunities. One student said, "I am just too lazy to learn another new social media platform. I like the one I used with my first language. That's good enough." 


\section{Implications}

These results provide some insight into the factors that prevent learners from using the target language in online environments. One consistent theme is the digital inequality participants feel: they do not see themselves as equal members of the community who have the autonomy to participate as they choose, but rather feel they are outsiders who are afraid of making mistakes and facing backlash from those who "belong" in the space. They also do not see the benefits of $\mathrm{CMC}$ for language learning that are presented in previous research (e.g., Abrams, 2008; Kern, 1995; Sullivan \& Pratt 1996; Warschauer, 1996, 1997), instead, seeing online environments as spaces that reinforce, rather than transform, existing power structures (Dooly, 2015; Jarboe, 2001; Ortega \& Zyzik, 2008).

Based on the results of this study, the question then becomes what educators do with this information; once we have a better understanding of some of the factors limiting target language participation, it is important to consider how learners can overcome these barriers. Table 4 synthesizes results from the three research questions in this study into key barriers and presents strategies educators can use to help overcome the challenges their learners encounter.

Table 4

Recommended Strategies to Overcome Barriers to Online Participation

\begin{tabular}{ll}
\hline Barriers & Strategies \\
\hline Language ability & -highlight the benefits of online environments as areas for \\
& experimentation, with lower stakes than face-to-face encounters \\
& (Kessler, 2018) \\
& -learners can create new anonymous accounts or user names, \\
& separate from what they may already be using (Fornara, 2018) \\
& -use scaffolded classroom activities and assignments where students \\
& can get feedback on the type of comments they might post online \\
& (Yang \& Chen, 2007) \\
\hline Use L1 to speak with friends and & -help learners find online affinity spaces around topics of interest where \\
family & personal, offline connections are less important (Thorne et al., 2015) \\
& -learners can be guided toward online spaces focused on the area \\
& where they are studying and living (Thorne et al., 2015) \\
\hline Skeptical of other users in anonymous & -acknowledge that learners are right to be skeptical of other users in \\
online settings & online environments, whether those environments are anonymous or \\
& not (Kessler, 2013) \\
& -teach learners to assess credibility using criteria such as Media \\
& Literacy Key Questions (National Association for Media Literacy \\
& Education, 2013) \\
-train learners on how to ignore trolls and focus on useful, constructive \\
comments (Kessler, 2013)
\end{tabular}




\begin{tabular}{ll}
\hline Barriers & Strategies \\
\hline Cultural issues & -train learners on developing pragmatic awareness within specific \\
& contexts through observation, analysis, and participation (Sykes, 2017) \\
& -use scaffolded bridging activities: begin with more controlled \\
& environments and strategies for specific content, then allow more \\
& freedom over time (Thorne \& Reinhard, 2008) \\
& -allow learners to choose environments or topics that they are \\
& interested in, where they can apply their background knowledge (Liu et \\
& al., 2015) \\
\hline Technical factors & -recognize that students from other countries, particularly China, may \\
& not be familiar with social media platforms popular in the United States \\
& (Yeh \& Mitric, 2019) \\
-train learners on the use and common practices of selected platforms & by using a cyclic approach and collaborative debriefings (Hubbard, \\
& $2013)$ \\
\hline
\end{tabular}

Most broadly, the barriers can be summarized in terms of the language learners use and encounter online, the interlocutors (or lack thereof) they use it with, and the environments in which these exchanges take place. These learners either do not believe online affinity spaces are viable for meaningful target-language communication, they are not aware of such environments (especially evident in the pretask question asking why participants do not use the target language online), or they lack the confidence to participate in them. The strategies shown in Table 4 present a holistic approach to increasing learner participation in these online spaces that includes providing feedback within scaffolded activities and learner training on the basic use of popular social media platforms. Instructors can also highlight the benefits of anonymity in these environments, where learners may feel more free to experiment and less afraid to make mistakes.

Two skills that are invaluable for anyone participating in online communities but particularly for language learners are pragmatic awareness and the evaluation of credibility. It is impossible for instructors to directly teach the diverse rules, norms, and expectations within the innumerable online settings learners may encounter; rather, instructors can teach strategies learners can use to increase pragmatic awareness within online affinity spaces of their own choosing (Sykes, 2017). It is also essential for learners to be able to evaluate online information effectively and efficiently. This is not only important in anonymous settings but in all online environments, though anonymous settings do provide particular challenges. The criteria within Fogg's (2003) Web Credibility Framework include the operator (or the source of the message), the content of the message, and the design of the site on which it appears. In the case of anonymous posts within a single platform, the source is unknown and the design is constant, so learners must be able to evaluate the credibility or usefulness of a message based solely on its content. They 
must also be able to do this efficiently, navigating the vast amount of online content and quickly discarding the messages they deem to be uncredible or in bad faith. These skills are challenging to develop, but they are important aspects of transferable digital literacy that are necessary for anyone participating in social media and the digital wilds.

\section{Conclusion}

This study represents a first step in identifying and removing barriers that keep ELLs from using the target language online. The findings are limited by the relatively small amount of data analyzed, in part, because so few participants had negative views of this type of interaction (e.g., only 14 out of 66 participants saying they were not likely to use this platform outside of class). Future studies with larger populations of participants could analyze patterns based around learner demographic factors, such as linguistic backgrounds and experience interacting in anonymous online environments. Participants also had limited exposure to the platform used in this study; future studies could investigate the issue more deeply by tracking learners' perceptions and behaviours over time as they become more familiar with the environment and begin participating on their own. This study was limited by the fact that learners were only exposed to one discussion thread within one forum (or "subreddit") selected by the researchers. This was done as a scaffolded way to investigate initial perspectives toward a new environment. However, future studies could better utilize Reddit as an online affinity space by allowing learners to select forums based on personal interests. Finally, future research could utilize other qualitative methods such as think-aloud protocols, screen recording, or eye-tracking to get a more comprehensive understanding of the challenges and barriers learners encounter in these online spaces.

The 21st Century Skills Map from the American Council on the Teaching of Foreign Languages (ACTFL, 2011) includes communication, technology literacy, and social and cross-cultural skills. Online affinity spaces within social media platforms present opportunities for learners to develop these skills in authentic social contexts; these opportunities may otherwise be lacking even for those learners studying in regions where the target language is spoken. But many learners will not find or participate in these online communities on their own, for the reasons highlighted in this study. By identifying the barriers that keep learners from participating in these communities and presenting strategies to reduce them, we hope that language educators can help students find new avenues for communication not only for language learning but also for social inclusion: meaningful language use among communities of like-minded people. 


\section{Notes}

1. Autonomous language learning in the digital wilds is defined as "informal online language learning platforms, communities, and networks that provide learning opportunities separate from formal instructional contexts" (Sauro \& Zourou, 2017, p. 186). Examples of digital wilds include fan fiction communities, digital games, online affinity groups, and other online spaces outside of traditional learning contexts that "present interesting, and perhaps even compelling, opportunities for intercultural exchange, agentive action, and meaning making" (Thorne, 2010, p. 144).

2. Four responses were discarded for not containing relevant information within this specific sample.

\section{The Authors}

Ellen Yeh, $\mathrm{PhD}$, is an assistant professor in the English and Creative Writing Department and serves as director of the English as an Additional Language Program at Columbia College Chicago. She holds a PhD in Curriculum and Instruction with a specialization in second language education from Ohio University. She also holds a Teaching English to Speakers of Other Languages (TESOL) Certificate and Computer Assisted Language Learning (CALL) Certificate. Her research interests include media literacy in teacher education, social media literacy, CALL, intercultural communication, and family diversity in education. She has published a research article titled "Voices to Be Heard: Using Social Media for Digital Storytelling to Foster Language Learners' Engagement." Her recent publications include the peer-reviewed "A Model for Mobile Social Media Integration in Constructivist ESL Classrooms," and "Intercultural Competence for Teachers of Young ELLs." In addition, her peer-reviewed article "Media Literacy Education and 21st-Century Teacher Education" was published by the International Encyclopedia of Media Literacy.

Nicholas Swinehart is a Multimedia Pedagogy Specialist at the University of Chicago. His research interests include blended synchronous learning environments and language learner participation in online communities. His previous publications include chapters in the Handbook of Research on Mobile Technology, Constructivism, and Meaningful Learning and the Handbook of Research on Learner-Centered Pedagogy in Teacher Education and Professional Development. He is a coauthor of Teaching Languages in Blended Synchronous Learning Classrooms: A Practical Guide.

\section{References}

Abrams, Z. (2003). Flaming in CMC: Prometheus' fire or Inferno's? CALICO Journal, 20(2), 245260.

Abrams, Z. (2008). Sociopragmatic features of learner-to-learner computer-mediated communication. CALICO Journal, 26(1), 1-27.

American Council on the Teaching of Foreign Languages. (ACTFL, 2011). ACTFL 21st Century Skills Map. Retrieved from http://www.p21.org/storage/documents/Skills\%20Map/p21_ worldlanguagesmap.pdf

Anwaruddin, S. M. (2019). Teaching language, promoting social justice: A dialogic approach to using social media. CALICO Journal, 36(1), 1-18.

Bouhnik, D., \& Deshen, M. (2014). WhatsApp goes to school: Mobile instant messaging between teachers and students. Journal of Information Technology Education: Research. 13, $217-231$.

Castells, M. (1997). The power of identity. Malden, MA: Blackwell. 
Comas-Quinn, A., De los Arcos, B., \& Mardomingo, R. (2012). Virtual learning environments (VLEs) for distance language learning: Shifting tutor roles in a contested space for interaction. Computer Assisted Language Learning, 25(2), 129-143. https://doi.org/10.1080/09588221. 2011.636055

Darhower, M. (2002). Interactional features of synchronous computer-mediated communication in the intermediate L2 class: A sociocultural case study. CALICO Journal, 19(2), 249-277.

DiMaggio, P. J., \& Hargittai, E. (2001). From the "digital divide" to "digital inequality": Studying Internet use as penetration increases. Working Paper 19. Princeton, NJ: Center for Arts and Cultural Policy Studies, Woodrow Wilson School, Princeton University.

Dooly, M. (2015). It takes research to build a community: Ongoing challenges for scholars in digitally-supported communicative language teaching. CALICO Journal, 32(1), 172-194.

Fogg, B. J. (2003). Persuasive technology: Using computers to change what we think and do. San Francisco: Morgan Kaufmann.

Fornara, F. (2018, March 13). Using Instagram to foster learners' autonomy for intercultural learning [Blog post]. Retrieved from http://fltmag.com/using-instagram-to-foster-learners-autonomy/

Gee, J. P. (2004). Situated language and learning: A critique of traditional schooling. New York, NY: Routledge.

Glass, C. R., \& Westmont, C. M. (2014). Comparative effects of belongingness on the academic success and cross-cultural interactions of domestic and international students. International Journal of Intercultural Relations, 38, 106-119.

Gleason, J., \& Suvorov, R. (2019). Promoting social justice with CALL. CALICO Journal, 36(1), i-vii.

Guo, Y., \& Beckett, G. (2007). The hegemony of English as a global language: Reclaiming local knowledge and culture in China. Convergence: International Journal of Adult Education, 40(1), 117-132.

Hampel, R., \& Pleines, C. (2013). Fostering student interaction and engagement in a virtual learning environment: An investigation into activity design and implementation. CALICO Journal, 30(3), 342-370. http://dx.doi.org/10.11139/cj.30.3.342-370

Hendrickson, B. (2018). Academic and socio-cultural adjustment among Asian international students in the Flemish community of Belgium: A photovoice project. International Journal of Intercultural Relations, 39, 66-81.

Hendrickson, B., Rosen, D., \& Aune, K. (2011). An analysis of friendship networks, social connectedness, homesickness, and satisfaction levels of international students. International Journal of Intercultural Relations, 35, 281-295.

Hubbard, P. (2013). Making a case for learner training in technology enhanced language learning environments. CALICO Journal, 30(2), 163-178.

Jarboe, K. P. (2001). Inclusion in the information age: Reframing the debate. Athena Alliance. Retrieved from https://www.issuelab.org/resources/2888/2888.pdf

Jenkins, H. (2006). Confronting the challenges of participatory culture: Media education for the 21st century. John D. and Catherine T. MacArthur Foundation.

Kern, R. (1995). Restructuring classroom interaction with networked computers: Effects on quantity and characteristics of language production. Modern Language Journal, 79(4), 457-476.

Kessler, G. (2013). Collaborative language learning in co-constructed participatory culture. CALICO Journal, 30(3), 307-322.

Kessler, G. (2018). Technology and the future of language teaching. Foreign Language Annals, 51(1), 205-218.

LeCompte, M. D., \& Schensul, J. J. (1999). Analyzing and interpreting ethnographic data. Walnut Creek, CA: AltaMira Press.

Liu, M., Abe, K., Cao, M., Liu, S., Ok, D. U., Park, J. B., Parrish, C. M., \& Sardegna, V. G. (2015). An analysis of social network websites for language learning: Implications for teaching and learning English as a Second Language. CALICO Journal, 32(1), 114-152. https://doi. org/10.1558/calico.v32i1.25963 
Miles, M. B., \& Huberman, A. M. (1994). Qualitative data analysis: An expanded sourcebook (2nd ed.). Thousand Oaks, CA: Sage Publications.

National Association for Media Literacy Education. (2013). Core principles of media literacy education. Retrieved from http://www.namle.net/publications/core-principles/

Ortega, L., and Zyzik, E. (2008). Online interactions and L2 learning: Some ethical challenges for L2 researchers. In S. Magnan (Ed.), Mediating discourse online, 331-355. Amsterdam: John Benjamins. https://doi.org//10.1075/aals.3.19ort

Saldaña, J. (2003). Longitudinal qualitative research: Analyzing change through time. Walnut Creek, CA: AltaMira Press.

Saldaña, J. (2015). The coding manual for qualitative researchers (3rd ed.). Los Angeles: SAGE Publications.

Sauro, S. (2017). Online fan practices and CALL. CALICO Journal, 34(2), 131-146.

Sauro, S., \& Zourou, K. (2017). CALL for papers for CALL in the Digital Wilds special issue. Language Learning \& Technology, 21(1), 186.

Stickler, U., \& Hampel, R. (2010). CyberDeutsch: Language production and user preferences in a Moodle virtual learning environment. CALICO Journal, 28(1), 49-73.

Stewart, A. (2000). Social inclusion: An introduction. In P. Askonas and A. Stewart (Eds.), Social inclusion: Possibilities and tensions (pp. 1-16). Houndmills, England: Macmillan.

Sullivan, N., \& Pratt, E. (1996). A comparative study of two ESL writing environments: A computer-assisted classroom and a traditional oral classroom. System, 24(4), 491-501.

Sykes, J. (2017). Technologies for teaching and learning intercultural competence and interlanguage pragmatics. In C. Chapelle \& S. Sauro (Eds.), The handbook of technology and second language teaching and learning (pp. 119-133). Hoboken, NJ: John Wiley \& Sons.

Thorne, S. L. (2010). The "intercultural turn" and language learning in the crucible of new media. In F. Helm \& S. Guth (Eds.), Telecollaboration 2.0 for language and intercultural learning (pp. 139-164). Bern, Switzerland: Peter Lang.

Thorne, S. L., \& Reinhardt, J. (2008). Bridging activities, new media literacies, and advanced foreign language proficiency. CALICO Journal, 25(3), 558-572.

Thorne, S. L., Sauro, S., \& Smith, B. (2015). Technologies, identities, and expressive activity. Annual Review of Applied Linguistics, 35, 215-233.

Toetenel, L. (2014). Social networking: A collaborative open educational resource. Computer Assisted Language Learning, 27(2), 149-162. https://doi.org/10.1080/09588221.2013.818561

Varonis, E. M., \& Gass, S. (1985). Non-native/non-native conversations: A model for negotiation of meaning. Applied Linguistics, 6(1), 71-90. https://doi.org/10.1093/applin/6.1.71

Warschauer, M. (1996). Comparing face-to-face and electronic discussion in the second language classroom. CALICO Journal, 13 (2\&3), 7-26.

Warschauer, M. (1997). Computer-mediated collaborative learning: Theory and practice. Modern Language Journal, 81(4), 470-481.

Warschauer, M. (2003). Technology and social inclusion: Rethinking the digital divide. Cambridge, MA: The MIT Press.

Wolcott, H. E. (1994). Transforming qualitative data: Description, analysis, and interpretation. Thousand Oaks, CA: Sage.

Yang, S. C., \& Chen, Y.-J. (2007). Technology-enhanced language learning: A case study. Computers in Human Behavior, 23, 860-879. doi: 10.1016/j.chb.2006.02.015

Yeh, E. \& Mitric, S. (2019). Voices to be heard: Using social media for digital storytelling to foster language learners' engagement. TESL-EJ (The Electronic Journal for English as a Second Language), 23(2). Retrieved from http://www.tesl-ej.org/wordpress/issues/volume23/ej90/ ej90int/

Zhang, J., \& Goodson, P. (2011). Predictors of international students' psychosocial adjustment to life in the United States: A systematic review. International Journal of Intercultural Relations, $35,139-162$. 
Zourou, K. (2012). On the attractiveness of social media for language learning: A look at the state of the art. Alsic: Apprentissage des Langues et Systèmes d'Information et de Communication, 15(1). 